\title{
Exportações e desenvolvimento econômico regional em Goiás
}

\author{
Andréa Freire de Lucena \\ Flávia Rezende Campos \\ Jane Figueredo Santos
}

\begin{abstract}
Resumo
O presente artigo tem o objetivo de analisar a relação existente entre o crescimento econômico dos municípios de Goiás e suas exportações. A fim de verificar esta relação foi estimado um modelo empírico com dados em painel para os 246 municípios goianos no período 2007-2017. O modelo estimou o Produto Interno Bruto em função das exportações, do consumo de energia elétrica da classe industrial e da classe comercial, e do total de vínculos empregatícios ativos. Foi realizada uma análise dos dados dos municípios com melhores posições no ranking de crescimento econômico em Goiás para verificar se aquelas que possuem maior crescimento econômico são as que mais exportam. Os resultados do modelo demonstraram uma relação positiva e significativa entre o nível de crescimento municipal e o valor exportado no período de 2007-2017. A comparação entre o ranking dos municípios e os resultados do modelo mostra que os municípios com maior crescimento econômico estão entre os que mais exportam no estado de Goiás.
\end{abstract}

Palavras-chave | Crescimento econômico regional; exportações; municípios; Goiás.

Classificação JEL | F14 O47 R11

Exports and regional economic growth in Goiás

\begin{abstract}
The present paper aims to study the relationship between the economic growth of the cities of Goiás and their exports. In order to verify the relationship between economic growth and exports it was estimated an empirical model with panel data for 246 cities of Goiás in the period 2007-2017. The model estimated the Gross Domestic Product (GDP) as a function of exports $(\mathrm{X})$, industrial and commercial energy consumption $(\mathrm{K})$, in $\mathrm{MWh}$, and the total number of active employment $(\mathrm{L})$. An analysis of the data of the cities with the best positions in the ranking of economic growth in the state was carried out, in order to verify if those with higher economic growth are those that export more. The results of the model showed a positive and significant relationship between the level of municipal growth and the value exported in the period 2007-
\end{abstract}


2017. The comparison between the ranking of cities and the results of the model shows that the cities with the highest economic growth are among those that export most in the state.

Keywords | Exports; Goiás; municipalities; regional economic growth.

JEL Classification | F14 O47 R11

\section{Exportaciones y crecimiento económico regional en el Estado de Goiás}

\section{Resumen}

El presente artículo tiene como objetivo estudiar la relación existente entre el crecimiento económico de los municipios de Goiás y sus exportaciones. Con el fin de verificar la relación entre crecimiento económico y exportaciones se estimó un modelo empírico con datos de panel para los 246 municipios goianos en el período 2007-2017. El modelo estimó el Producto Interno Bruto en función de las exportaciones, del consumo de energía eléctrica industrial y comercial, y del total de relaciones laborales activas. También se realizó un análisis de los datos de los municipios con mejores posiciones en el ranking de crecimiento económico en Goiás para verificar si los que tienen mayor crecimiento económico son los que más exportan. Los resultados del modelo mostraron una relación positiva y significativa entre el nivel de crecimiento municipal y el valor exportado en el período 2007-2017. La comparación entre el ranking de los municipios y los resultados del modelo muestra que las ciudades con mayor crecimiento económico se encuentran entre las que más exportan en el estado de Goiás.

Palabras clave | Crecimiento económico regional; exportaciones; municipios; Goiás.

Clasificación JEL | F14 O47 R11

\section{Introdução}

Ao tratar de economia, uma das grandes preocupações refere-se ao crescimento econômico de uma nação ou região, que pode ser influenciado por diversos fatores como investimento, produção, comercializações domésticas e internacionais. Ao longo da história econômica, as exportações têm contribuído para o crescimento e aberto caminho para o desenvolvimento nas diversas regiões do país, por meio de aumento da demanda para os produtos nacionais e, consequentemente, da renda. No que diz respeito à relação existente entre crescimento e exportação, pode-se compreendê-la a partir das contribuições de teóricos que estudaram o comércio internacional. Para Adam Smith (2008), as exportações de mercadorias, quando são superiores às importações, aumentam a riqueza de um Estado. David Ricardo (1996) afirma que o que gera fluidez às exportações de um país tende a produzir acúmulo de dinheiro. 
Partindo do pressuposto de que o crescimento econômico de um país é influenciado pelas exportações, alguns autores verificaram o que pode incrementá-las. Smith (2008) e Ricardo (1996), defenderam a especialização produtiva. Eles destacaram que aquele país que fabricar um bem com maior produtividade do trabalho terá uma vantagem absoluta, para Smith (2008), e comparativa, para Ricardo (1996), na exportação do bem. Eli Heckscher e Bertil Ohlin asseveraram que um país exporta bens que utilizam fatores de produção que ele possui em abundância (JONES, 1956). A vantagem comparativa está na relação entre os recursos que um país possui e a tecnologia de produção que ele utiliza (KRUGMAN; OBSTFELD; MELITZ, 2015). Staffan Linder (1961) adotou a proposição de que um produto é potencialmente exportável se ele for consumido (ou receber investimento) no país de origem. Raymond Vernon (1966) enfatizou que os produtos negociáveis no exterior são aqueles que possuem dinâmica inovadora e estão passíveis às economias de escala.

Gershon Feder (1982), elaborou uma estrutura analítica para verificar a possibilidade de as produtividades marginais serem diferentes nos setores exportadores e não exportadores e encontrou evidências empíricas que mostraram que as produtividades marginais são mais elevadas nos setores que exportam. Cabe destacar que trabalhos como os de Kohli e Singh (1989), Vohra (2001), Ibrahim e MacPhee (2003), Hameed, Chaudhary e Khan (2005), Nanda e Panda (2011) e Ajmi, Aye, Balcilar e Gupta (2015) mostraram que as exportações influenciaram positivamente o crescimento econômico dos países analisados.

Outra forma de compreender a relação entre crescimento e exportações é por meio das pesquisas que levaram em consideração a dimensão regional. Vários trabalhos sobre essa relação foram produzidos para as regiões brasileiras, como no caso de Souza (2002), que estudou a relação entre as duas grandezas econômicas para o estado do Rio Grande do Sul. Outro exemplo é o estudo de Piffer (2009), que também realizou esta análise para o estado de Paraná, bem como o de Barbosa e Alvim (2007), que buscaram entender a relação entre exportações e crescimento econômico no Brasil entre 1996 e 2005. Galimberti e Caldart (2010) investigaram os municípios do Conselho Regional de Desenvolvimento (Corede) Serra, no Rio Grande do Sul. Carmo, Raiher e Stege (2017), por sua vez, fizeram uma análise espacial com dados em painel para as microrregiões brasileiras. Todos encontraram uma relação positiva entre o crescimento econômico de cada região e seu nível de exportações.

Torna-se necessário ainda mencionar que diversos estudos sobre este tema destacam a relevância da teoria da base exportadora. Para esta teoria, o setor exportador tem a capacidade de dinamizar a economia local e de propagar efeitos multiplicadores sobre ela, fazendo com que se desenvolva. Nesse sentido, o setor exportador tem sido de grande importância para esse processo de crescimento, caracterizando-se como uma condição necessária, mas não suficiente, para o desenvolvimento regional, como ressaltou North (1977). 
Por meio das exportações, as regiões passam a ter o resto do mundo como um possível mercado consumidor, em vez de se limitar à região em que está localizada. Dessa forma, a internacionalização permite - por meio, por exemplo, de dotações iniciais de recursos, como no caso da mineração no município de Alto Horizonte, em Goiás - que o produto se torne competitivo o suficiente para ganhar espaço no cenário internacional. Neste caso, o município ou região tem a possibilidade de aumentar a sua demanda e, consequentemente, seu produto, o que pode se traduzir em crescimento. $\mathrm{O}$ contato com o mercado externo e o aumento da produção também favorecem os ganhos de escala, a especialização e os ganhos de aprendizagem, entre outros elementos que são benéficos à economia, como a aglomeração de outras indústrias que dão suporte ao setor exportador e se desenvolvem com ele. Assim, torna-se relevante investigar se as unidades federativas brasileiras que estão obtendo elevadas taxas de crescimento econômico nos últimos anos, como Goiás, estão também alcançando patamares ascendentes nos níveis de exportação.

As exportações goianas têm sido predominantemente incrementadas no período 1999-2019, com um crescimento de 370\%. Em dezembro de 2019, 8,4\% das exportações goianas eram provenientes da indústria extrativa, 59,1\% da indústria de transformação e 32,4\% da agropecuária. Goiás, em 2019, exportou 1.093 produtos diferentes para 163 mercados internacionais, principalmente soja ( $23 \%$ do total), carne bovina fresca, refrigerada ou congelada (14\%), milho não moído, exceto milho doce $(12 \%)$, e farelo de soja e outros alimentos para animais (11\%) (MINISTÉRIO DA ECONOMIA, 2020).

A partir dessas considerações, o objetivo do artigo é investigar se os municípios que mais exportam em Goiás são aqueles que têm apresentado maior crescimento econômico. O método utilizado para verificar a relação entre crescimento econômico e exportações para o caso dos municípios goianos foi o econométrico, por meio da técnica de dados em painel para os 246 municípios goianos no período 2007-2017. O modelo empírico estimou o Produto Interno Bruto (PIB) em termos das exportações $(X)$, do consumo de energia industrial e comercial em MWh $(K)$ e do total de vínculos empregatícios ativos (L).

\section{Crescimento regional e exportações}

As questões regionais precedem a economia clássica, a exemplo da teoria de rendimento crescente da terra em função de sua localização, de Willliam Petty. O fator locacional esteve presente nas principais escolas de pensamento econômico e diversos autores embutiram a noção de espaço em suas teorias - direta ou indiretamente - como, por exemplo, Richard Cantillon, Adam Smith, David Ricardo e Alfred Marshall, entre outros. Com o crescimento econômico e o 
aumento das desigualdades, a problemática regional se tornou um tema cada vez mais recorrente (SOUZA, 2009).

O crescimento econômico foi analisado a partir de diversas perspectivas, entre elas a teoria dos polos de crescimento, de François Perroux, de 1955, que defendia que o crescimento não ocorre de maneira igualitária temporalmente e geograficamente, mas, sim, concentrado em localidades, que ele denominou de polos, contrastando com a teoria clássica de crescimento equilibrado (RIPPEL, 2009). Perroux também criticava a abstração do território feita pela análise neoclássica, abandonando a noção de espaço abstrato utilizada por essa teoria e fazendo uso do conceito de espaço polarizado (MARCHIORO, 2014). Os polos, segundo a teoria de Perroux, são impulsionados inicialmente por uma indústria motriz, ou indústria-chave. Ela deve ser capaz de modificar a estrutura econômica e social de uma região gerando, dessa forma, economias de aglomeração (SOUZA, 2009).

Além disso, Perroux ressaltava que a indústria motriz pode provocar mudanças estruturais nos polos, gerando externalidades positivas e negativas, bem como forças de atração (centrípetas) e forças de repulsão (centrífugas) que levam ao surgimento ou desaparecimento de empresas. Tais mudanças fazem com que os fatores de produção se desloquem e se aglomerem nas regiões com crescimento mais elevado, distribuindo-se, dessa forma, de modo desigual ao longo do território (MARCHIORO, 2014). Um país, para Perroux, é composto por vários núcleos de crescimento, que são organizados hierarquicamente e heterogeneamente ao longo do território, formando-se a partir de fatores internos que levam à indústria a se instalar em determinado local, gerando economias de aglomeração que se difundem na economia por meio de preços, fluxos e antecipações. Essas economias iniciam o processo de crescimento e, conforme o aglomerado cresce, sua área de influência também aumenta, impactando mais partes do território e configurando-se em polos de desenvolvimento (SOUZA, 2009).

Tal como Perroux, Douglass North (1977) preconizava que para o crescimento de uma região é necessário um impulso inicial, algo que mova e dinamize a economia, a exemplo do setor exportador. Para North, esse setor é condição necessária - mas não suficiente - para o crescimento e o desenvolvimento de uma localidade, o que foi traduzido na Teoria da Base de Exportação. A base de exportação desempenha um papel vital na geração de renda e na formação de centros modais, que se expandem em função de vantagens locacionais, reduzindo custos. $\mathrm{O}$ aglomerado se torna um centro comercial que atrai empresas que apoiam a atividade principal. A melhoria no desempenho nas exportações, seja por aumento da competitividade seja por lançamento de outros produtos leva, consequentemente, a uma melhora na condição econômica (AREND, 2010).

North destacou que o desenvolvimento de uma região está em grande parte associado à forma de utilização da renda gerada com a exportação. Se uma região angaria uma elevada renda com as exportações, mas tem um alto nível de 
importações, a renda gerada pelas exportações será de pouco proveito para a região, visto que os lucros serão remetidos para fora (NORTH, 1977). Dessa forma, além de ser necessário um setor exportador dinâmico e com elevado nível de crescimento, a região também precisa de uma produção interna que acompanhe o desenvolvimento trazido pelo setor exportador.

A problemática regional, para North, situa-se na capacidade de a região se inserir no mercado mundial por meio das exportações e, neste contexto, a capacidade de imersão da economia nacional no cenário mundial influencia na possibilidade de a região manter um crescimento sustentado e diversificar sua produção (NORTH, 1977). É relevante destacar que apesar de inicialmente o crescimento dos setores passivos (aqueles que produzem apenas para o consumo interno) dependerem do crescimento do setor exportador, eles também podem passar a ser exportadores, conforme aconteça o aumento da produção e a redução dos custos de transação ligados à exportação (LINS et al., 2012).

Segundo a teoria da base exportadora, o sucesso das exportações foi fator determinante para o crescimento econômico de algumas regiões — que não passaram por todos os estágios da economia, que vai da subsistência até a industrialização — como no caso dos Estados Unidos e do Canadá no século XIX. North também defendia a ideia de que um país não precisa ter sua base exportadora em produtos manufaturados para ter crescimento sustentado, pois a industrialização da economia ocorreria à medida em que a renda e a poupança da região aumentassem, e, depois de atender à demanda local, esses produtos também poderiam ser exportados (LINS et al., 2012).

Para North (1977), as dotações iniciais da região determinam quais serão os bens que ela deve exportar, podendo ser manufaturado ou primário. Se as condições da região não são favoráveis para a instalação de uma atividade econômica que promova modificações na estrutura econômica e social, trazendo, dessa forma, crescimento e desenvolvimento, o Estado deve intervir a fim de gerar condições atrativas para instalação de uma empresa.

Tanto a teoria dos polos de crescimento como a da base exportadora encontraram diversas aplicações práticas e foram utilizadas por vários autores para explicar a trajetória de desenvolvimento das regiões que analisaram. Os estudos de Rippel (2009) apontaram que o desenvolvimento e surgimento de polos de crescimento têm alavancado o crescimento do estado do Paraná em função da dotação inicial favorável detida pelo estado, que é a localização da região. Outra vantagem do estado é que os polos são interligados, facilitando a negociação entre si e a difusão dos efeitos propulsores, destacados por Perroux, para outras partes do estado.

Marchioro (2014), identificou a Zona Franca de Manaus como uma aplicação prática da teoria dos polos de crescimento. Para a autora, a Zona Franca de Manaus seria um espaço polarizado, que age como um campo de força, surgido devido à concentração populacional e produtiva. As economias de aglomeração advindas da 
criação da Zona Franca de Manaus trouxeram para a região a retomada do crescimento e a modificação da atividade produtiva, propagando um melhor desempenho econômico para outras regiões do estado.

Para além dos trabalhos empíricos que discutiram os efeitos das economias de aglomeração, outros estudos, como os de Tyler (1982), Fasano Filho (1988) e Pinheiro (1992), contribuíram para evidenciar a relação entre exportações e crescimento, explicitada por North. Tyler (1982) procurou averiguar as fontes de crescimento da demanda da indústria de transformação brasileira no período 19701979. O resultado obtido foi que tanto as exportações como a política de substituições de importações contribuíram para o aumento do PIB no período analisado.

Fasano Filho (1988), utilizando dados do período 1969-1984, analisou o impacto das exportações de manufaturados sobre o crescimento da economia, concluindo que as taxas de crescimento econômico elevadas estavam associadas às maiores taxas de exportações de produtos manufaturados. Assim, as exportações têm efeito positivo sobre o crescimento, levando ao aumento dos investimentos e tornando a industrialização mais propícia (PINHEIRO, 1992). Esses fatores conduzem ao progresso tecnológico e ao aumento da eficiência técnica, gerando aumento da produtividade.

Barbosa e Alvim (2007) apontaram diversos estudos que mostraram a relação positiva entre exportações e crescimento econômico, como no caso de Zestos e Tao (2002), que verificaram, por meio da economia de escala advinda da especialização produtiva e devido à possibilidade de acesso a níveis mais elevados de tecnologia, bem como maior capital - que as regiões em contato com o mercado internacional têm -, que as economias cresceram mais. O estudo foi realizado com a utilização de dados para o período 1948-1996 para os Estados Unidos e Canadá, sendo que as variáveis consideradas foram exportações, importações e crescimento econômico. Os resultados obtidos indicam relações bidirecionais entre o comércio exterior e o produto para os dois países.

Os trabalhos apresentados anteriormente reforçam com evidências empíricas as teorias que defendem que as exportações afetam o crescimento econômico, como na Teoria de Base de Exportação (NORTH, 1977). A estimativa da promoção do crescimento econômico por meio das exportações tem sido testada por regressões da variável PIB e da variável exportação, usando técnicas econométricas (BARBOSA; ALVIM, 2007), em que a significância estatística do coeficiente de variação da exportação corrobora a hipótese de que estas promovem o crescimento econômico. Feder (1982), analisou as fontes de crescimento para um grupo de países menos desenvolvidos (semi-industrializados) no período de 1964-1973, mostrando que a produtividade marginal dos fatores pode apresentar diferenças nos setores de exportação e de não exportação da economia. Por meio da análise econométrica, foi indicado que a produtividade tende a ser maior nos setores 
exportadores, porém, existem externalidades geradas desses setores mais produtivos para os setores não exportadores, menos produtivos.

A formulação apresentada pelo autor elucida os efeitos benéficos do volume de exportações ou dos setores exportadores para os demais a partir da introdução de técnicas de produção mais aprimoradas, treinamento da mão de obra e fluxo estável de insumos importados. Feder (1982) mostra que esses efeitos são referidos como externalidades, uma vez que não se refletem nos preços de mercado. A estrutura analítica desenvolvida pelo autor pode ser utilizada em outros estudos usando dados detalhados, de modo que a extensão do diferencial de produtividade em grupos específicos de países, estados ou regiões pode ser avaliada.

Carmo et al. (2017) analisaram empiricamente os efeitos das exportações sobre o crescimento econômico das microrregiões brasileiras no período de 2000-2010, a partir do modelo de Feder (1982). Os resultados constataram que as exportações aumentaram o crescimento econômico por meio do diferencial de produtividade existente entre o setor exportador e o não exportador, bem como pela externalidade positiva gerada pelo setor exportador sobre o setor não exportador (spillovers). Em suma, Carmo et al. (2017) mostraram que as exportações apresentaram efeitos indiretos sobre o crescimento econômico das microrregiões brasileiras. Essa constatação corrobora a hipótese de Feder (1982) de que as exportações contribuem para o crescimento do PIB mais do que apenas o incremento no volume de exportações, extrapolando a mera correlação positiva entre crescimento das exportações e da renda nacional, uma vez que as exportações são um componente da produção agregada.

\section{Metodologia}

Este trabalho tem por objetivo verificar a relação existente entre o nível de crescimento dos municípios do estado de Goiás e seu volume de exportações. Para cumprir tal objetivo, optou-se pela utilização de um modelo de regressão econométrico por dados empilhados em painel, que é uma regressão em que uma unidade de corte transversal é analisada ao longo de um período (GUJARATI; PORTER, 2012). A escolha do método econométrico, que significa "medição econômica", não implica uma tentativa de estabelecer uma relação causal ou determinística entre as variáveis, visto que a atividade econômica possui infinitos desdobramento e conjunturas, mas, sim, estabelecer uma relação estatística entre o crescimento e as variáveis explicativas que proporcione uma melhora no entendimento das mesmas. 
Quadro 1 - Divisão dos municípios por região de planejamento

\begin{tabular}{|lc|}
\hline Região de planejamento & Quantidade de municípios \\
\hline Oeste Goiano & 43 \\
Centro Goiano & 31 \\
Norte Goiano & 26 \\
Sul Goiano & 26 \\
Sudoeste Goiano & 26 \\
Sudeste Goiano & 22 \\
Metropolitana de Goiânia & 20 \\
Nordeste Goiano & 20 \\
Entorno do DF & 20 \\
Noroeste Goiano & 19 \\
\hline
\end{tabular}

Fonte: Elaborado pelas autoras com base nos dados do IMB, 2020.

Estimou-se uma regressão para 246 municípios, que foram divididos em 10 regiões de planejamento ${ }^{1}$, conforme mostra o quadro 1 . Por meio dos valores observados e dos coeficientes estimados, buscou-se obter uma relação entre o nível de crescimento dos municípios e suas exportações e verificar como cada variável contribuiu para o crescimento econômico. Os dados estão disponíveis em séries temporais e foram organizados em uma planilha dividida por municípios, variável de análise e ano de referência, compondo uma planilha de dados em painel. Depois, estimou-se o modelo de regressão, conforme a equação 1, para os anos de 20072017.

$$
Y=\beta 0+\beta 1 X+\beta 2 K+\beta 3 L+\mu
$$

Os dados de exportação foram coletados junto ao Ministério da Economia, originalmente em dólares, e, posteriormente, convertidos para real com as informações de câmbio disponíveis no Instituto de Pesquisa Econômica Aplicada (IPEA). Eles estão classificados de acordo com o domicílio fiscal da empresa exportadora, podendo se diferenciar da classificação por origem do produto. Para a

\footnotetext{
${ }^{1}$ O governo de Goiás definiu 10 Regiões de Planejamento, repartindo, dessa forma, os 246 municípios. Cada região foi definida de acordo com um critério, sendo eles: por determinações de leis, como a Região Metropolitana de Goiânia (Lei Complementar Estadual no 27 de dezembro de 1999, modificada pela Lei Complementar Estadual $n^{\circ}$ 54 de 23 de maio de 2005) e a região do Entorno do Distrito Federal (Lei Complementar (Constituição Federal) $n^{\circ}$ 94, de 19 de fevereiro de 1998); em função de sua homogeneidade em termos de condições socioeconômicas e espaciais e como estratégia de planejamento para investimentos governamentais tendo em vista minimizar os desequilíbrios regionais, no caso das regiões Norte e Nordeste; e de acordo com os principais eixos rodoviários do estado, que se aplica para as outras seis regiões.
} 
variável capital $(\mathrm{K})$ foi usado o nível de consumo de energia elétrica da classe industrial e comercial (MWh) como proxy, ou seja, uma variável que faz uma medição indireta de outra, devido à impossibilidade de mensuração da variável original, para o nível de investimento da economia. Considerou-se que quanto maior o nível de consumo de energia maior está sendo o uso da capacidade produtiva do município.

Os dados foram extraídos junto ao Instituto Mauro Borges de Estatísticas e Estudos Socioeconômicos (IMB) bem como a variável trabalho (L), aqui mensurada como o total de vínculos empregatícios ativos. Os dados a respeito do PIB (Y) foram extraídos do banco de dados eletrônico do Instituto Brasileiro de Geografia e Estatística (IBGE), disponíveis até o ano de 2017. O $\beta 0$ foi estimado para captar o nível de crescimento autônomo, e $\mu$ é um termo de erro que representa todos os fatores que afetam o nível de crescimento, mas que não foram explicitados pela regressão acima.

\section{Exportações e o crescimento econômico regional de Goiás}

As exportações em Goiás sofreram algumas oscilações ao longo do tempo, mas, ainda assim, apresentaram crescimento no período analisado. Em 2007, o valor das exportações era de US $\$ 2,41$ bilhões, enquanto em 2017 o saldo foi de US $\$ 5,53$ bilhões, baseado principalmente em produtos básicos que sempre tiveram maior representatividade nas exportações do estado. Em 2006, os produtos básicos representavam cerca de $80 \%$ dos produtos exportados. Uma década depois, em 2016, este valor caiu para 68,3\% devido ao aumento da participação dos produtos manufaturados, que era de 13,9\%, em 2006, e passou a ser de 26,7\%, em 2016. Esse resultado significa que o estado fabricou produtos com maior valor agregado (MINISTÉRIO DA ECONOMIA, 2020).

Ao analisar as regiões de planejamento de Goiás, pode-se notar que elas se alternaram como região que mais exporta, como pode ser observado no quadro 2 , devido à dispersão entre as regiões de planejamento dos municípios com maior potencial exportador do estado. Para verificar a relação entre exportações e crescimento econômico foram analisadas as duas regiões que apresentaram maior crescimento em termos de valor das exportações no período analisado.

As regiões que mais cresceram em volume de exportações, de acordo com o quadro 2, foram a Centro e a Sudoeste do estado. Em 2007, a região Centro exportava um valor de US $\$ 74$ milhões, chegando, ao final de 2017, a um montante de US $\$ 573$ milhões. Essa diferença significou um aumento de suas exportações em quase sete vezes, puxado principalmente pelos municípios de Anápolis (soja e derivados), Goianésia (açúcar e sacarose) e Pilar de Goiás (ouro). O produto da região aumentou em torno de $176 \%$ de 2007 a 2017. 
Quadro 2 - Classificação das regiões em valor das exportações

\begin{tabular}{|lccccccccccc|}
\hline Região de Planejamento & 2007 & 2008 & 2009 & 2010 & 2011 & 2012 & 2013 & 2014 & 2015 & 2016 & 2017 \\
\hline Sudoeste Goiano & $4^{\circ}$ & $7^{\circ}$ & $4^{\circ}$ & $2^{\circ}$ & $2^{\circ}$ & $1^{\circ}$ & $1^{\circ}$ & $1^{\circ}$ & $1^{\circ}$ & $1^{\circ}$ & $1^{\circ}$ \\
Norte Goiano & $1^{\circ}$ & $1^{\circ}$ & $1^{\circ}$ & $1^{\circ}$ & $1^{\circ}$ & $2^{\circ}$ & $2^{\circ}$ & $2^{\circ}$ & $2^{\circ}$ & $2^{\circ}$ & $2^{\circ}$ \\
Centro Goiano & $8^{\circ}$ & $8^{\circ}$ & $8^{\circ}$ & $8^{\circ}$ & $6^{\circ}$ & $3^{\circ}$ & $3^{\circ}$ & $3^{\circ}$ & $3^{\circ}$ & $3^{\circ}$ & $4^{\circ}$ \\
Oeste Goiano & $6^{\circ}$ & $6^{\circ}$ & $6^{\circ}$ & $5^{\circ}$ & $7^{\circ}$ & $7^{\circ}$ & $6^{\circ}$ & $6^{\circ}$ & $7^{\circ}$ & $7^{\circ}$ & $6^{\circ}$ \\
Metropolitana de Goiânia & $3^{\circ}$ & $5^{\circ}$ & $7^{\circ}$ & $7^{\circ}$ & $8^{\circ}$ & $8^{\circ}$ & $8^{\circ}$ & $5^{\circ}$ & $6^{\circ}$ & $6^{\circ}$ & $7^{\circ}$ \\
Sudeste Goiano & $5^{\circ}$ & $3^{\circ}$ & $3^{\circ}$ & $6^{\circ}$ & $5^{\circ}$ & $6^{\circ}$ & $7^{\circ}$ & $7^{\circ}$ & $5^{\circ}$ & $5^{\circ}$ & $3^{\circ}$ \\
Entorno do DF & $7^{\circ}$ & $4^{\circ}$ & $2^{\circ}$ & $3^{\circ}$ & $3^{\circ}$ & $5^{\circ}$ & $5^{\circ}$ & $8^{\circ}$ & $8^{\circ}$ & $8^{\circ}$ & $8^{\circ}$ \\
Sul Goiano & $2^{\circ}$ & $2^{\circ}$ & $5^{\circ}$ & $4^{\circ}$ & $4^{\circ}$ & $4^{\circ}$ & $4^{\circ}$ & $4^{\circ}$ & $4^{\circ}$ & $4^{\circ}$ & $5^{\circ}$ \\
Noroeste Goiano & $9^{\circ}$ & $9^{\circ}$ & $9^{\circ}$ & $9^{\circ}$ & $9^{\circ}$ & $9^{\circ}$ & $9^{\circ}$ & $9^{\circ}$ & $9^{\circ}$ & $9^{\circ}$ & $9^{\circ}$ \\
Nordeste Goiano & $10^{\circ}$ & $10^{\circ}$ & $10^{\circ}$ & $10^{\circ}$ & $10^{\circ}$ & $10^{\circ}$ & $10^{\circ}$ & $10^{\circ}$ & $10^{\circ}$ & $10^{\circ}$ & $1^{\circ}$ \\
\hline
\end{tabular}

Fonte: Elaboração das autoras com base nos dados do Ministério da Economia, 2020 e do IMB, 2020.

A região Sudoeste apresentou um montante de exportações de US $\$ 273$ milhões em 2007, e US $\$ 1,68$ bilhões em 2017. Os principais exportadores desta região são os municípios de Rio Verde, que foi o com maior valor em exportações em 2017, com base principalmente em produto do agronegócio; Quirinópolis, que tem como principal produto exportado a cana de açúcar; e Jataí, que exporta produtos primários. Essa região apresentou um crescimento econômico de 199\% ao longo desses 11 anos.

A relação entre o crescimento econômico do município e as exportações se mostrou positiva ao longo do período analisado. Dentre os 10 municípios que mais exportaram entre 2007 e 2017 não houve muitas modificações daqueles que compõem o ranking, havendo mais alterações na posição dos municípios dentro do ranking. O ranking de 2019 para exportações só insere o município de Goiânia (que

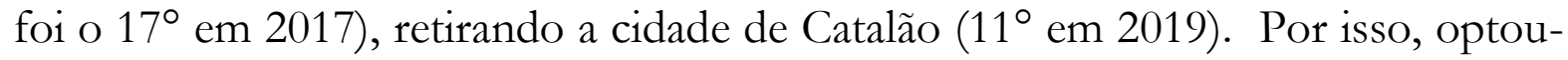
se por realizar uma análise mais profunda do ranking dos municípios em 2017, além da disponibilidade de dados referente ao PIB por município. 
Figura 1 - Ranking dos municípios de acordo com o respectivo PIB, 2017

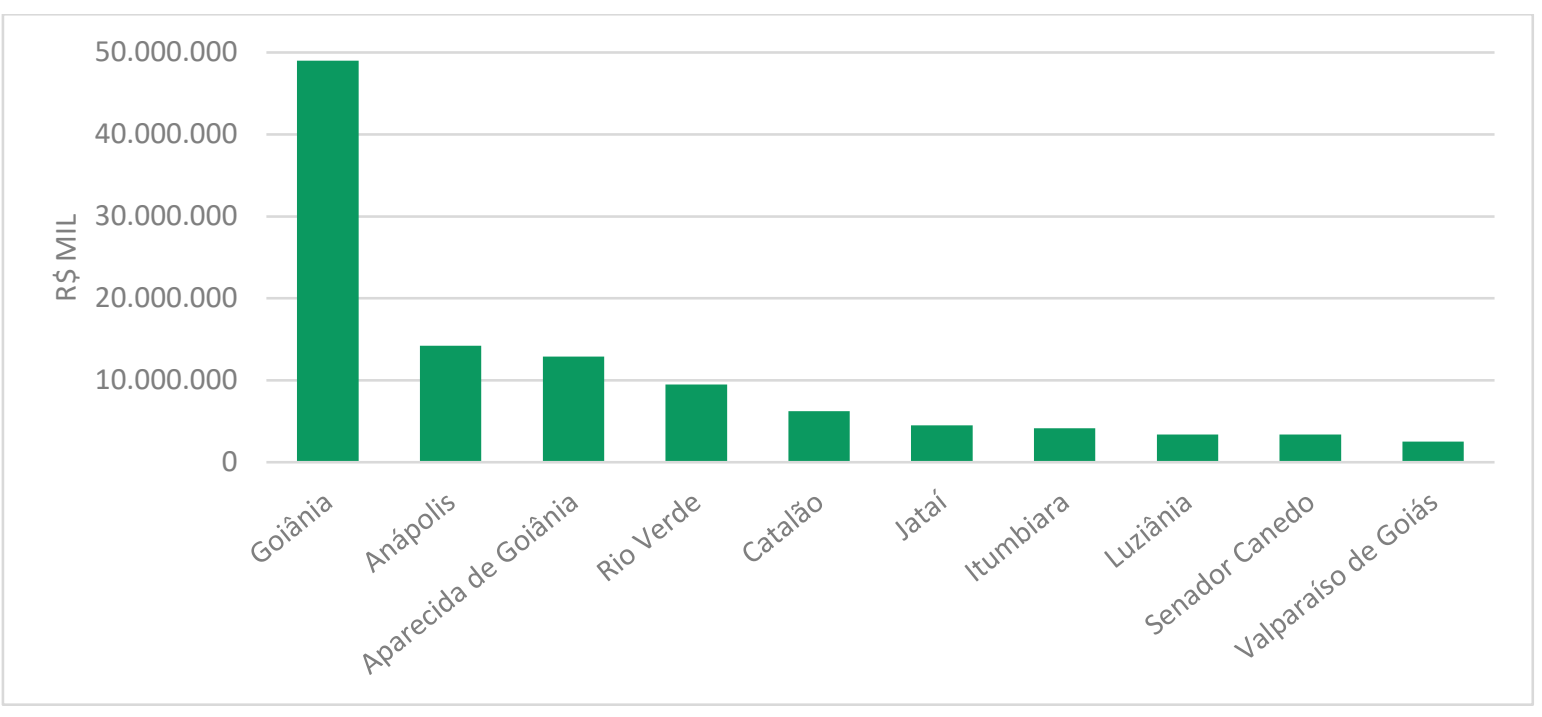

Fonte: Elaboração das autoras com base nos dados do IBGE, 2020.

Goiás ainda tem elevada concentração de renda: entre os 246 municípios, os que possuem os 10 maiores PIBs concentram 57\% da riqueza gerada no estado. Esses mesmos municípios detinham, em 2017, aproximadamente 61\% do valor das exportações do estado, demonstrando que a maior renda e as exportações estão concentradas em poucos municípios de Goiás.

Rio Verde foi o município que apresentou maior valor de exportações para o ano de 2017, sendo o quarto em termos de PIB e o segundo no ranking do Índice de Desempenho Econômico por Municípios (IDM) - Economia. Em 2009, Rio Verde foi considerado o segundo município mais competitivo do estado, em uma classificação feita pelo Instituto Mauro Borges de Estatísticas e Estudos Socioeconômicos (2020), que levava em conta o dinamismo econômico do município, riqueza gerada por ele, infraestrutura logística e tecnológica, a qualidade de vida da população, a mão de obra e as políticas de incentivos financeiros e tributários do município. O caso de Rio Verde é um exemplo prático da teoria dos polos de crescimento de Perroux, em que a instalação de indústrias motrizes aumenta o dinamismo de uma região e contribui para o seu desenvolvimento, e um caso paradigmático de sucesso, como assevera Macedo (2013). 
Figura 2-Ranking dos municípios exportadores, 2017

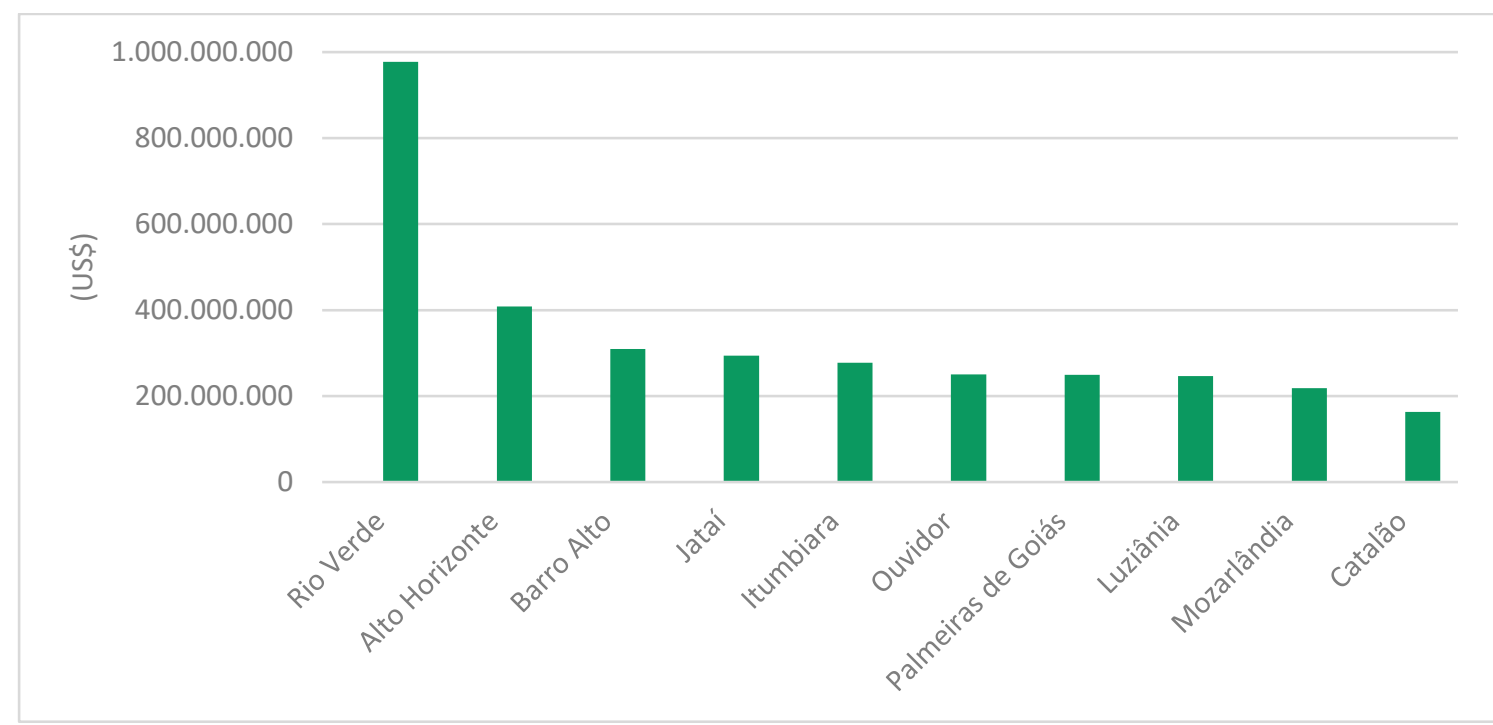

Fonte: Elaboração das autoras com base nos dados do Ministério da Economia, 2020.

Alto Horizonte se insere no cenário mundial em 2007 por meio da exportação de minério de cobre. O município é considerado pequeno em número de habitantes, mas se configura com um dos principais centros do estado em termos de minérios. Ainda em 2007 o PIB do município apresentou um aumento de 1480\% com relação a 2006. Nesse sentido, Alto Horizonte é considerado como um município de médio porte com crescimento acima da média estadual para a maioria dos anos. Alto Horizonte não está inserido entre os maiores PIB do estado, mas tem um Índice de Desenvolvimento Municipal (IDM) de 4,99 para 2018. Portanto, ele pode ser considerado um polo de crescimento encravado por não gerar efeitos de encadeamento para outras áreas, não dando origem, dessa forma, a uma região de influência em torno da indústria-chave do município (SOUZA, 2009).

Barro Alto é outro município que não faz parte dos maiores em termos de valor corrente do PIB, mas demostra relação positiva entre o PIB e as exportações, pois ao iniciar suas exportações, em 2011, a taxa de crescimento do PIB quase dobrou, passando de $33 \%$, em 2010, para 52\%, em 2011, e um crescimento de $151 \%$, em 2012. O município ainda ficou em sexto lugar no ranking do IDM economia no ano de 2018 e, assim como Alto Horizonte, também é um polo encravado. Jataí é o sexto município com maior PIB do estado e o quarto em exportações, com a produção voltada principalmente para itens agrícolas e derivados.

O quinto no ranking de 2017 foi Itumbiara, que é um dos municípios com maior crescimento econômico no estado. A principal atividade do município situa-se no ramo de produção agroindustrial. Itumbiara apresentou o sétimo maior PIB estadual, em 2017, bem como o sexto município mais competitivo em 2009. Ainda que o município de Ouvidor não esteja no topo dos PIBs do estado, as exportações 
têm colaborado para o crescimento de sua economia. No ano de 2018, o município foi o sétimo em termos de desempenho econômico, medido pelo IDM economia. A relação entre as variáveis é explicitada principalmente nos anos de 2009, quando um aumento das exportações foi acompanhado por um crescimento da renda do município, bem como no ano de 2010, quando a queda das exportações repercutiu na redução do PIB. Esse fenômeno demonstra a natureza recíproca de influência de uma variável sobre outra, e, ainda, a importância de ter um setor exportador forte para momentos de estagnação do mercado interno.

A sétima posição no ranking fica com o município de Palmeiras de Goiás que, apesar de não apresentar um dos maiores PIBs do estado, foi considerado, em 2009, o $13^{\circ}$ município mais competitivo em Goiás, com destaque, principalmente, na área de dinamismo, qualidade de vida e infraestrutura econômica e estratégia logística. $\mathrm{O}$ município de Luziânia ocupa o oitavo lugar no ranking de exportações de Goiás, em 2017, e exportou principalmente soja, milho, algodão e conservas.

Ao contrário dos outros municípios deste ranking está Mozarlândia, cuja economia está baseada na produção bovina, em que o volume de exportações não apresentou relação direta com o crescimento econômico do município. Catalão se posiciona como o quinto em termos de PIB em 2017 e o $10^{\circ}$ em relação às exportações, cuja fatia expressiva é de aparelhos mecânicos e máquinas, apresentando uma relação positiva entre o PIB e as vendas externas.

\section{Resultados do modelo}

A partir da equação 1 foi possível verificar as relações estatísticas e a significância das variáveis sobre o nível de crescimento econômico. Primeiramente foi estimado o modelo polled (painel com dados empilhados) e, em seguida, foi estimado o modelo com efeitos aleatórios. Pelo resultado do teste LM de Breusch-Pagan, rejeita-se a hipótese nula de que há adequação do modelo polled em relação ao modelo de efeitos aleatórios. Na sequência, foi estimado o modelo com efeitos fixos.

O teste $\mathrm{F}$ de Chow, que é apresentado ao se estimar o modelo de efeitos fixos, permite que se rejeite a hipótese nula de que há igualdade de interceptos e inclinações para todos os municípios (polled). Depois, foi realizado o teste de Hausman, por meio do qual se opta pela rejeição da hipótese nula de que o modelo de efeitos aleatórios oferece estimativas dos parâmetros do modelo mais consistentes do que as apresentadas pelo modelo de efeitos fixos. Em seguida, foi realizado o teste de Wooldridge para detecção de correlação serial, por meio do qual se rejeita a hipótese nula de ausência de autocorrelação. Por fim, o teste de Wald modificado para heterocedasticidade indicou também que se deve rejeitar a hipótese nula de ausência de heterocedasticidade e, com isso, decidiu-se estimar os modelos 
com erros-padrão robustos. Os resultados dos modelos podem ser vistos no quadro 3.

\section{Quadro 3 - Resultados dos modelos}

\begin{tabular}{|lccccc|}
\hline Variável & POLS_rob & FE & FE_rob & RE & RE_rob \\
\hline X & .630048 & 1.045376 & 1.045376 & 1.370806 & 1.370806 \\
& 0.0000 & 0.0000 & 0.0000 & 0.0000 & 0.0000 \\
K & 8.503052 & 3.912494 & 3.912494 & 5.503309 & 5.503309 \\
L & 0.0000 & 0.0000 & 0.238 & 0.0000 & 0.057 \\
& 48.77589 & 159.5814 & 159.5814 & 61.40384 & 61.40384 \\
_cons & 0.0000 & 0.0000 & 0.0000 & 0.0000 & 0.0000 \\
& 67558.93 & -465697.5 & -465697.5 & 32668.59 & 32668.59 \\
& 0.0000 & 0.0000 & 0.0000 & 0.272 & 0.273 \\
N & & & & & \\
r2 & 2706 & 2706 & 2706 & 2706 & 2706 \\
r2_o & 0.9450 & & & & \\
r2_b & & 0.9322 & 0.9322 & 0.9430 & 0.9430 \\
r2_w & & 0.9693 & 0.9693 & 0.9792 & 0.9792 \\
F & 0.7736 & 0.7736 & 0.7021 & 0.7021 \\
chi2 & 15469.74 & 2798.40 & 1840.65 & & \\
\hline
\end{tabular}

Fonte: Elaboração das autoras.

Todos os resultados dos modelos se apresentaram significativos, ou seja, as variáveis independentes, em conjunto, são significativas para explicação do PIB municipal de Goiás. A variável trabalho foi significativa em todos os modelos, o que indica que quanto maior o nível de emprego mais os municípios goianos obtêm crescimento. $\mathrm{O}$ investimento não se mostrou significativo para o nível de crescimento dos municípios no modelo de efeitos fixos com erro-padrão robusto e foi pouco significativo (somente a 10\% de significância) no modelo de efeitos aleatórios com erro-padrão robusto. A não significância do investimento talvez possa ser explicada pela proxy escolhida, nível de consumo de energia elétrica da classe industrial e da comercial (MWh), não ser a mais adequada para captar os efeitos dos investimentos porque muitas empresas exportadoras estão no meio rural. $\mathrm{O}$ fato de $68,3 \%$ dos produtos exportados por Goiás em 2016 serem de produtos básicos e a principal região de planejamento exportadora, a Sudoeste, possuir municípios, como Quirinópolis e Jataí, cujos principais bens exportados são produtos primários, podem indicar a necessidade de considerar o nível de consumo de energia elétrica da classe rural nos próximos estudos. 
As exportações, por fim, foram significativas em todos os resultados, mostrando que um aumento das exportações do município tem impacto positivo para o crescimento econômico dos municípios de Goiás. Essa constatação, apesar de ser alcançada a partir do uso de uma metodologia distinta dos vários estudos mencionados no artigo, reafirma os resultados dos trabalhos empíricos de Souza (2002), Piffer (2009), Barbosa e Alvim (2007) e Galimberti e Caldart (2010).

\section{Considerações finais}

O artigo se propôs a analisar a relação entre o crescimento econômico regional e o montante de exportações dos municípios goianos e verificar se os municípios que possuíam maior crescimento eram os que mais exportavam. Foram levantados dados junto aos órgãos que monitoram as variáveis, como Ministério da Economia e o Instituto Mauro Borges de Estatísticas e Estudos Socioeconômicos (IMB), que viabilizaram a estimação das exportações. Vale destacar que um maior nível de crescimento econômico propicia um maior dinamismo para o setor exportador e que um maior nível de exportações também possibilita um grau mais elevado de crescimento. Matos (2003, p. 37), em uma nota técnica emitida pelo Banco Central, destaca essa relação mútua entre crescimento e exportações: "A conclusão geral é que predominam efeitos bidirecionais entre crescimento econômico e exportações, indicando que as duas variáveis retroalimentam-se. São, portanto, determinadas conjuntamente".

A primeira análise dos dados foi feita por meio do ranking das regiões de planejamento e dos municípios em 2017, que se assemelha muito ao ranking dos últimos 10 anos, a exemplo de 2019, quando ocorreu alteração de apenas um município (com relação a 2017) dentre os 10 que possuem maior valor de exportações. Os dados de 2017 demonstraram que, dentre os 10 municípios de maior driver exportador, cinco deles (Rio Verde, Catalão, Jataí, Itumbiara e Luziânia) estão entre os com maior PIB, com aproximadamente $14 \%$ do total do produto do estado e 35\% das exportações totais de Goiás.

Mesmo no caso dos municípios que não se enquadram no ranking de maior PIB do estado, foi encontrada correlação entre o nível de crescimento e as exportações no período analisado. Nestes municípios, a taxa de crescimento é acima da média estadual, como pode ser visto no caso de Alto Horizonte e de Ouvidor. A exceção é Mozarlândia, que não demonstrou relação aparente entre o nível de crescimento e as exportações. As variáveis elencadas para estimar o crescimento econômico (PIB), como exportações (X), do consumo de energia industrial e comercial em MWh $(\mathrm{K})$ e do total de vínculos empregatícios ativos (L), demonstraram que a relação entre crescimento econômico goiano e exportações é positiva e significativa. Deste modo, na medida em que o município apresenta maior nível de exportações também apresenta maior crescimento. 
As exportações goianas têm sido um elemento de dinamismo para a região por meio do aumento de demanda, que gera ganhos de escala e diminuição dos custos de produção, e da aglomeração das empresas, que propicia externalidades positivas às empresas exportadoras na região. O crescimento das exportações nos municípios goianos cria empregos e contribui para a manutenção da renda e a geração de crescimento econômico, o que se reflete nos indicadores de renda e competitividade dos municípios exportadores. Nem todos os municípios, contudo, conseguiram propagar efeitos de encadeamento positivos e gerar crescimento para a região, como Alto Horizonte e Barro Alto, que são exemplos de polos encravados.

Para que os ganhos com as exportações se traduzam em crescimento para o município, conforme destaca North (1977), é fundamental que a renda gerada seja gasta no município, sendo necessário, portanto, um mercado interno que dê base para que o setor exportador cresça com ele. A história brasileira já demonstrou que quando não há crescimento do mercado interno e os lucros das exportações são todos remetidos para fora do país via importações, criam-se novos problemas como uma balança comercial desequilibrada e um país vulnerável às flutuações externas, podendo este ser um tema de próximos estudos sobre a relação entre exportações e crescimento para os municípios de Goiás.

\section{Referências}

AJMI, A. N.; AYE, G. C.; BALCILAR, M.; GUPTA, R. Causality between exports and economic growth in South Africa: evidence from linear and nonlinear tests. The Journal of Developing Areas, Nashville, v. 49, n. 2, p. 163-181, 2015.

AREND, S. C.; ORLOWSKI, R. F. O desenvolvimento regional da AMOSC a partir das teorias da base exportadora e dos polos de crescimento. Redes, Santa Cruz do Sul, v. 17, n. 1, p. 141-163, jan./abr. 2012.

BARBOSA, E; ALVIM, A. M. Exportações estaduais e crescimento econômico no Brasil, 1996 a 2005. Porto Alegre: PUCRS, 2007. 129p. (= Texto para Discussão, n. 2).

CARMO, A. S. S.; RAIHER, A. P.; STEGE, A. L. O efeito das exportações no crescimento econômico das microrregiões brasileiras: uma análise espacial com dados em painel. Estudos Econômicos, São Paulo, v. 47, n. 1, p. 153-183, 2017. 
FASANO FILHO, U. A expansão das exportações e o crescimento econômico: o caso do Brasil, 1969- 84. Revista Brasileira de Economia, Rio de Janeiro, v. 42, n. 1, p. 73-82, 1988.

FEDER, G. On exports and economic growth. Journal of Development Studies, Amsterdam, v. 12, n. 1-2, p. 59-73, 1983.

GALIMBERTI, J. K.; CALDART, W. L. As exportações e o crescimento econômico: análise dos municípios do Corede Serra, 1997-04. Ensaios FEE, Porto Alegre, v. 31, n. 1, p. 87-112, 2010.

GUjARATI, Damodar N.; PORTER, Dawn C. Econometria básica. Porto Alegre: AMGH, 2012.

HAMEED, A.; CHAUDHARY, M. A.; KHAN, K. Y. The growth impact of exports in South Asian countries. Pakistan Development Review, Islamabad, v. 44, n. 4, Part II, p. 901-919, 2005.

IBGE. Produto Interno Bruto dos Municípios. Rio de Janeiro: Instituto Brasileiro de Geografia e Estatísticas. Disponível em: https://www.ibge.gov.br/estatisticas/economicas/contas-nacionais/9088-

produto-interno-bruto-dos-municipios.html? $=\& \mathrm{t}=\mathrm{O}$-que-e. Acesso em: 18 nov. 2020 .

IBRAHIM, I.; MACPHEE, C. R. Export externalities and economic growth. Journal of International Trade \& Economic Development, London, v. 12, n. 3, p. 257-283, 2003.

IMB. Estatísticas. Goiânia: - Instituto Mauro Borges de Estatísticas e Estudos Socioeconômicos. Disponível em: http://www.imb.go.gov.br/. Acesso em: 20 nov. 2020 .

JONES, R. W. Factor proportions and the Heckscher-Ohlin Theorem. Review of Economic Studies, Oxford, v. 24, n. 1, p. 1-10, 1956. 
KOHLI, I.; SINGH, N. Exports and growth: critical minimum effort and diminishing returns. Journal of Development Economics, Amsterdam, v. 30, n. 2, p. 391-400, 1989.

LINDER, S. B. An essay on trade and transformation. New York: John Wiley \& Sons, 1961.

LINS, A. E.; LIMA, J. P. R.; GATTO, M. R. Uma aplicação da teoria da base exportadora para o caso do Nordeste. Revista Econômica do Nordeste, Fortaleza, v. 43, n. 1, p. 9-32, 2012.

MACEDO, F. C. Transformação econômica, inserção externa e dinâmica territorial no Centro-Oeste brasileiro: o caso de Rio Verde. Sociedade \& Natureza, Uberlândia, v. 25, n. 1, p. 35-50, jan./abr. 2013.

MATOS, O. C. Inter-relações entre desenvolvimento financeiro, exportações e crescimento econômico: análise da experiência brasileira. Brasília: Banco Central do Brasil. Brasília, 2003. (= Nota Técnica, n. 40).

MARCHIORO, L. W.; GUBERT, D.; GUBERT, V. A teoria dos polos de crescimento e desenvolvimento de Perroux e a implantação da Zona Franca de Manaus na Região Norte do Brasil. Revista de Estudos Sociais, Cuiabá, v. 16, n. 31, p. 186-202, 2014.

MINISTÉRIO DA ECONOMIA. Comex Stat. Disponível em: http://comexstat.mdic.gov.br/pt/home. Acesso em: 10 nov. 2020.

NANDA, S.; PANDA, A. K. An empirical assessment of export led growth hypothesis in the context of Indian economy. Indian Journal of Economics \& Business, New Delhi, v. 10, n. 4, p. 481-494, 2011.

NORTH, D. A agricultura no crescimento econômico regional. In: SCHWARTZMAN, J. (Org.) Economia regional: textos selecionados. Belo Horizonte: CEDEPLAR, p. 133-143, 1977. 
PIFFER, M. A teoria da base econômica e o desenvolvimento regional do estado do Paraná no final do século XX. 2009. Tese (Doutorado em Desenvolvimento Regional) - Universidade de Santa Cruz do Sul, Santa Cruz do Sul, 2009.

PINHEIRO, A. C. O crescimento da produtividade total dos fatores e a estratégia de promoção de exportações: uma revisão da evidência internacional. Pesquisa e Planejamento Econômico, Rio de Janeiro, v. 22, n. 1, p. 1-33, 1992.

RICARDO, D. Princípios de economia política e tributação (= Os Economistas). São Paulo: Ed. Nova Cultural, 1996.

RIPPEL, R.; LIMA, J. F. Polos de crescimento econômico: notas sobre o caso do estado do Paraná. Redes, Santa Cruz do Sul, v. 14, n.1, p. 136-149, 2009.

SOUZA, N. J. Exportações e crescimento econômico do RS, 1951/2001. Ensaios FEE, Porto Alegre, v. 23, número especial, p. 565-602, 2002.

SOUZA, N. J. Desenvolvimento Regional. São Paulo: Atlas, 2009.

SMITH, A. A riqueza das nações: investigação sobre sua natureza e suas causas. Rio de Janeiro: Zahar Editores, 2008. (v. 1).

TYLER, W. G. Substituição de importações e expansão das exportações como fontes de crescimento industrial no Brasil. Estudos Econômicos, São Paulo, v. 12, n. 3, p. 125-134, 1982.

VERNON, R. International investment and international trade in the product cycle. The Quarterly Journal of Economics, Oxford, v. 80, n. 2, p. 190-207, 1966.

VOHRA, R. Export and economic growth: further time series evidence from lessdeveloped countries. International Advances in Economic Research, London, v. 7, n. 3, p. 345-350, 2001. 
ZESTOS, G. K.; TAO, X. Trade and GDP growth: causal relations in the United States and Canada. Southern Economic Journal, Hoboken/NJ, v. 68, n. 4, p. 859874, 2002.

Data de submissão: 07/04/2020

Data de aprovação: 07/01/2021

Revisão: Daniela Matthes (português), Anderson de Miranda Gomes (inglês) e Yanet

María Reimondo Barrios (espanhol).

\section{Andréa Freire de Lucena}

Faculdade de Administração Ciências Contábeis e Ciências Econômicas /

Universidade Federal de Goiás (Campus Samambaia)

Rua Samambaia, s/n - Chácaras Califórnia

74001-970 Goiânia/GO, Brasil

Orcid: http://orcid.org/0000-0003-2984-3688

E-mail: andflucena@gmail.com

\section{Flávia Rezende Campos}

Faculdade de Administração Ciências Contábeis e Ciências Econômicas /

Universidade Federal de Goiás (Campus Samambaia)

Rua Samambaia, s/n - Chácaras Califórnia

74001-970 Goiânia/GO, Brasil

Orcid: http://orcid.org/0000-0003-1362-101X

E-mail: flaviarezende@hotmail.com

Jane Figueredo Santos

Departamento de Planejamento e Controle / Enel Brasil

Rua 2, 505 - Jardim Goiás

74805-180 Goiânia/GO, Brasil

Orcid: http://orcid.org/0000-0003-2598-7756

E-mail: jane_figueredo@hotmail.com 
Andréa Freire de Lucena, Flávia Rezende Campos e Jane Figueredo Santos 